\title{
Modelagem para estimativa de carga e umidade do material combustível em área de Cerrado
}

\author{
Micael Moreira Santos ${ }^{\mathrm{a}^{*}}$, Thatyana Santiago Martins ${ }^{\mathrm{a}}$, Damiana Beatriz Silva ${ }^{\mathrm{a}}$, Jader Nunes Cachoeira, \\ Gil Rodriques Santos ${ }^{\mathrm{a}}$, Marcos Giongo ${ }^{\mathrm{a}}$ \\ ${ }^{a}$ Universidade Federal do Tocantins, Brasil \\ *Autor correspondente (moreirasmicael@gmail.com)
}

\section{N F O}

\section{Keywords}

modeling

fuel moisture

fuel load estimate

\section{Palavras-chaves}

modelagem

umidade do

combustível

estimativa de carga

\begin{abstract}
A B S T R A C T
Modeling for estimation of load and moisture of fuel in Cerrado area.

The objective of the present work was to evaluate regression models to estimate fuel moisture as a function of meteorological variables, as well as to estimate fuel load as a function of dendrometric variables and litter height, in an area of Cerrado stricto sensu in the southern state of Tocantins. Field meteorological data were obtained through a weather station, which made records throughout the experiment period. The experiment took place during 7 months, totaling 10 collections, in sporadic days. The fuel was collected every 5 minutes, was transferred in a plastic container and its mass determined with the aid of a scale, and after that, it was placed in paper bags. The samples were dried in greenhouses at a temperature of $75^{\circ} \mathrm{C}$ to constant weight and reweighed to obtain the dry material mass. The correlation obtained between fuel humidity and the temperature was an inverse of -0.81 , and a direct correlation between fuel humidity and relative air humidity of 0.80 . $\mathrm{R}^{2}$ aj values for fuel material moisture estimation models ranged from -0.02 to 0.67 and for load estimates $\mathrm{R}^{2} \mathrm{aj}$ ranged from 0.55 to 0.78 . The results show that the humidity of Cerrado stricto sensu fuel can be estimated by linear regression models.
\end{abstract}

\section{R E S U M O}

O objetivo do presente trabalho foi avaliar modelos de regressão para estimativa da umidade do material combustível em função das variáveis meteorológicas, bem como para estimativa de carga de material combustível em função de variáveis dendrométricas e espessura da manta, em uma área de Cerrado stricto sensu no sul do estado Tocantins. Os dados meteorológicos em campo foram obtidos através de uma estação meteorológica, a qual fez registros durante todo o período de experimento. O experimento ocorreu durante 7 meses, totalizando 10 coletas, em dias esporádicos. O material combustível foi coletado de 5 em 5 minutos, eram transferidos em recipiente plástico e determinado sua massa com auxílio de uma balança, e após isso acondicionado em sacos de papel. As amostras foram secadas em estufas a uma temperatura de $75^{\circ} \mathrm{C}$ até peso constante, e novamente pesadas para obter a massa do material seco. A correlação obtida entre umidade do combustível e a temperatura foi inversa de $-0,81$, e uma correlação direta entre a umidade do combustível e a umidade relativa do ar de 0,80 . Os valores de $\mathrm{R}^{2}$ aj para os modelos de estimativa de umidade do material combustível variaram de $-0,02$ a 0,67 e para estimativa de carga o $\mathrm{R}^{2}$ aj variou de 0,55 a 0,78 . Os resultados obtidos demonstram que a umidade do material combustível de Cerrado stricto sensu pode ser estimada através de modelos de regressão linear. 


\section{INTRODUÇÃO}

O Cerrado é o segundo maior bioma brasileiro, com 2,04 milhões de quilômetros quadrados, superado em extensão apenas pela Amazônia e ocupando $21 \%$ de todo o território nacional (Klink \& Machado, 2005), com registro de presença de fogo que remota de mais de 32 mil anos atrás (Pereira Junior, 2002). Esse bioma possui fitofisionomias adaptadas aos incêndios florestais, sendo essa presença constante de fogo o fator responsável pela seleção natural da fauna e da flora com estruturas de adaptação a perturbação que o incêndio causa no ambiente (Pivello, 2010).

Os incêndios no Cerrado podem acontecer de duas maneiras, através da ação antrópica e por causas naturais. A primeira, causada pela ação antrópica, o homem se utiliza do fogo com o objetivo de fazer a limpeza de uma área, manejo de pastagem, caça de animais, e controle de animais peçonhentos. Ainda, o fogo pode ocorrer também de forma negligente e criminosa (Pereira Junior, 2002). Ramos (1995) descreve que a segunda forma de ocorrência de incêndios no cerrado é a natural, onde o fator de ignição são os raios, e essa configuração é considerada menos agressiva, já que, como os raios geralmente precedem as chuvas, as queimadas são suprimidas logo após o seu início.

A umidade do material combustível é uma variável que está ligada diretamente ao comportamento do fogo, controlando a inflamabilidade dos combustíveis, sendo, portanto, o resultado direto entre a interação do clima e das condições atmosféricas, podendo sofrer variações com muita facilidade. (Soares \& Batista, 2007).

Segundo Alves (2009) e Batista (1984), a umidade do material combustível vem sendo estimada no Brasil de forma direta através de amostragem no campo, onde o material combustível é coletado em recipientes para ser pesado, posteriormente seco em laboratório por no mínimo 24 horas, e pesado novamente, encontrando assim a umidade do material combustível. O processo direto é demorado e dispendioso a medida que ocorre o aumento da área a ser amostrada.

Segundo Batista (1984) a outra forma de obter a umidade de material combustível é através do uso de indicadores, sendo estes elementos padronizados e com características definidas, para que dessa maneira o seu conteúdo possa ser rapidamente determinado e esteja estreitamente relacionado com a umidade do material combustível. Dessa maneira, é importante o desenvolvimento de formas indiretas para estimar o conteúdo da umidade do material combustível, através de informações de mais fácil obtenção, tornando assim essa determinação mais rápida e menos onerosa, tendo em vista a importância que o fator umidade do material combustível exerce sobre os incêndios florestais (Alves, 2009; Batista, 1984).

Neste contexto, este trabalho teve como objetivo avaliar modelos de regressão para estimativa da umidade do material combustível em função das variáveis meteorológicas, bem como para estimativa de carga de material combustível em função de variáveis dendrométricas e espessura da manta, em uma área de Cerrado stricto sensu no sul do estado Tocantins.

\section{MATERIAL E MÉTODOS}

\section{Área de estudo}

A área de estudo localiza-se no município de Gurupi (Figura 1), sul do estado do Tocantins, atitude de $11^{\circ} 70^{\prime} 46^{\prime}$ 'S e longitude $49^{\circ} 08^{\prime} 27^{\prime}$ ' $O$ e altitude em média de $287 \mathrm{~m}$. As coletas foram realizadas na Universidade Federal do Tocantins - Campus de Gurupi, onde existe uma área com remanescente do bioma Cerrado stricto sensu.

Este estudo foi realizado no município de $\mathrm{Gu}$ rupi, Tocantins. A origem do nome Gurupi vem do tupi-guarani que significa "Diamante Puro", é conhecida como a capital da amizade, localizando-se ao sul do Tocantins a $214 \mathrm{~km}$ de Palmas capital do estado. Gurupi é considerada a terceira maior cidade do estado, tendo como principal fonte de renda a pecuária e a agricultura (Portal da Prefeitura, 2019). Após a realização da coleta de dados, simulações numéricas com o modelo SIR foram realizadas no Laboratório de Matemática e Química Computacional (LABMAQC) localizado na Universidade Federal do Tocantins (UFT), Campus de Gurupi.

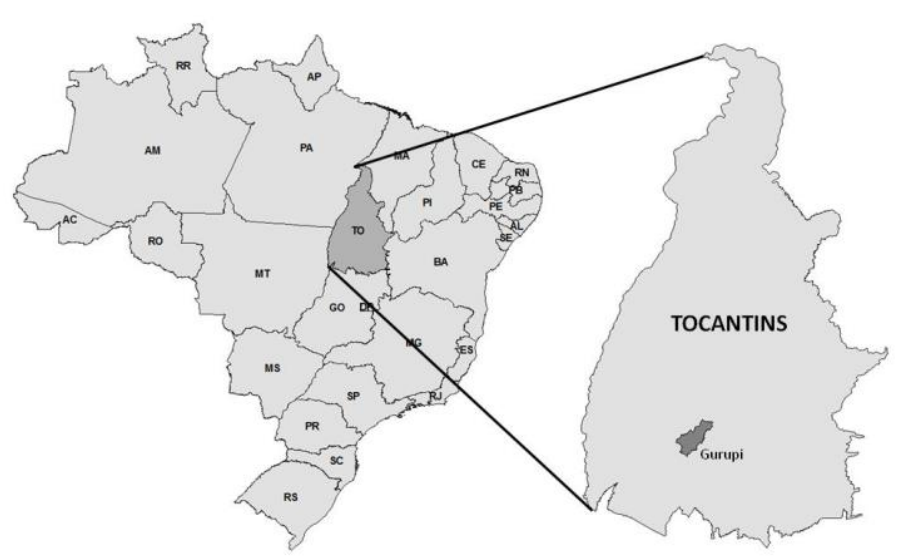

Figura 1 - Localização do município de Gurupi(TO). 


\section{Clima}

Com base na classificação climática de Thornthwaite o clima do local de estudo é BlwA'a', caracterizado por um clima úmido com moderada deficiência hídrica no inverno, evapotranspiração potencial com média anual variando de $1.400 \mathrm{e}$ $1.700 \mathrm{~mm}$, distribuindo-se no verão em torno de 390 e $480 \mathrm{~mm}$ ao longo dos três meses consecutivos com temperatura mais elevada (Seplan, 2012).

$\mathrm{Na}$ figura 2 é apresentado um climograma com os dados de precipitação mensal, temperatura máxima diária, e temperatura mensal, e temperatura mínima diária, obtidos na Estação Meteorológica do município de Gurupi, mantida pelo INMET. Essa série constam os dados dos anos de 1975 a 1990, onde é possível observar que durante os me- ses de maio, junho, julho e agosto, a lâmina precipitada é inferior e menor que $50 \mathrm{~mm}$ e as temperaturas são as mais altas do ano, acima de $30^{\circ} \mathrm{C}$.

Assim como a precipitação e a temperatura, durante os meses que vão de maio a agosto começa a ocorrer a queda de umidade relativa do ar e aumento da evaporação, conforme demonstrado na figura 3.

Assim como as outras variáveis meteorológicas, com a Velocidade do vento mensal e a insolação mensal (Figura 4) ocorre uma drástica variação durante os meses de inverno, tornando a região do Cerrado extremamente vulnerável ao fogo, já que a umidade relativa sofre uma queda, e a temperatura, insolação, evaporação, velocidade do vento, sofrem um drástico aumento, influenciando no risco e comportamento do fogo.

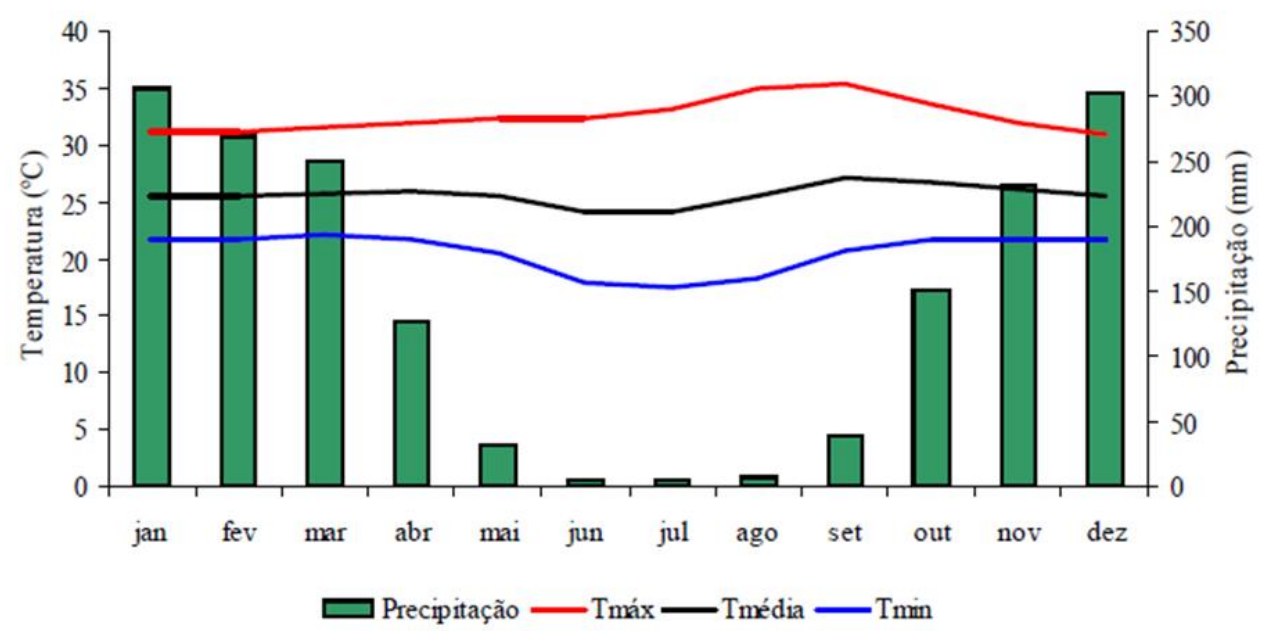

Fonte: INMET (1992)

Figura 2 - Médias de precipitação mensal, temperatura máxima diária (Tmáx), temperatura mensal (Tmédia) e temperatura mínima diária (Tmin) na Estação Meteorológica de Gurupi.

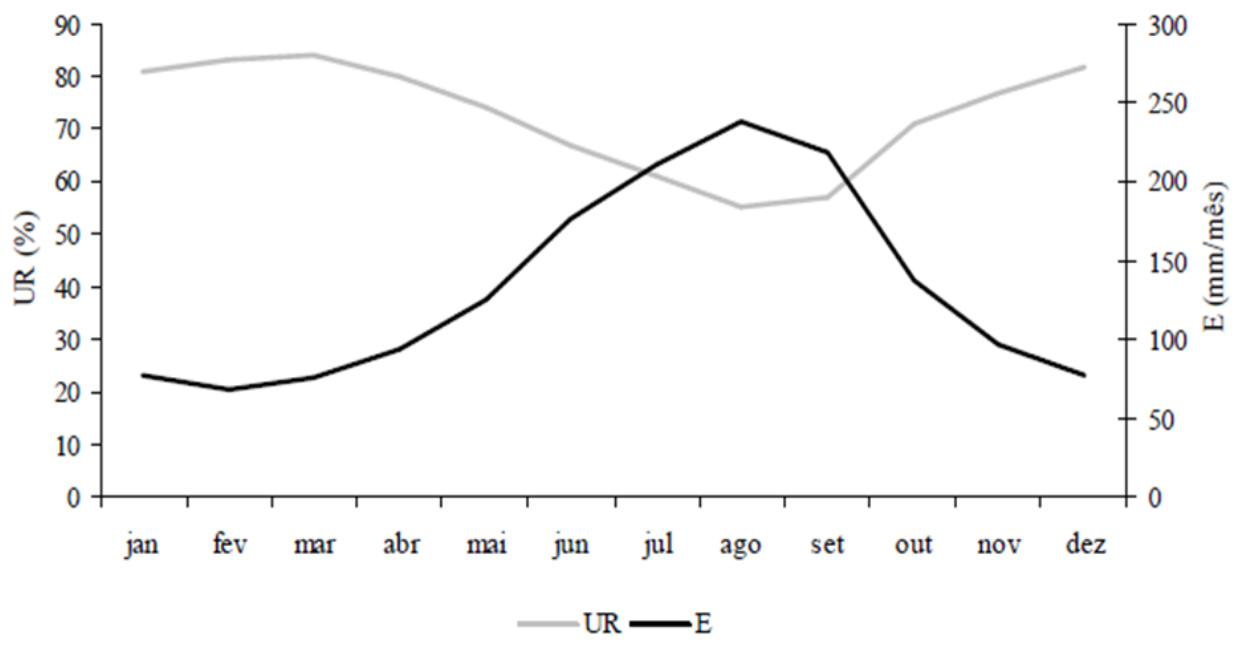

Fonte: INMET (1992)

Figura 3 - Médias de umidade relativa mensal (UR) e lâmina evaporada mensal (E) para Estação Meteorológica de Gurupi. 




Fonte: INMET (1992)

Figura 4 - Médias de velocidade do vento mensal (Vv) e insolação mensal (I) para a Estação Meteorológica de Gurupi.

\section{Desenvolvimento das Atividades}

A primeira etapa do trabalho consistiu em um planejamento, no qual foram estabelecidos os devidos locais que seriam realizadas as amostragens das variáveis florestais para o desenvolvimento dos modelos matemáticos. Foram alocadas 38 parcelas distribuídas de forma aleatória nas áreas com tipologia vegetal de Cerrado stricto sensu, buscando uma representação das variáveis florestais de interesse.

Para a determinação da localização das unidades amostrais, foram utilizadas imagens de satélite do sensor LANDSAT 5/TM e base vetorial de uso do solo do estado do Tocantins disponibilizado pela Secretaria de Planejamento e Modernização da Gestão Pública (Seplan) do estado do Tocantins. Nas áreas com a presença das tipologias de Cerrado stricto sensu foram distribuídos 38 pontos, os quais correspondiam ao centro das unidades amostrais. Após a alocação das parcelas, as coordenadas UTM (Universal Transverse Mercator) de cada parcela foram importadas para um GPS de navegação para que posteriormente em campo pudesse ser feito a localização e execução dos trabalhos de campo. Além disso, foram também elaborados mapas de localização e as trajetórias a serem percorridas para a materialização das parcelas. Essa atividade teve como objetivo principal facilitar os acessos às áreas, reduzir o tempo na localização dos pontos amostrais, redução de custos e melhorar, de forma geral, a logística envolvida para a execução das atividades.

\section{Levantamento de campo}

Os levantamentos de campo ocorreram durante os meses de outubro, novembro e dezembro de 2011, para os dados utilizados na elaboração dos modelos matemáticos para a estimativa da quantidade do material combustível. Já para a elaboração dos modelos para a estimativa da umidade do material combustível, os dados foram coletados no início do mês de janeiro de 2012.

As coletas das amostras foram feitas em intervalos de 5 minutos, sendo amostrado o material combustível superficial com o auxílio de um recipiente plástico. Após cada coleta, o material era acondicionado em sacos de papel Kraft com a sua devida identificação e pesado em uma balança de precisão $0,01 \mathrm{~g}$.

Os dados meteorológicos foram obtidos de forma simultânea à amostragem do material combustível por meio de uma miniestação meteorológica, com uma precisão de $\pm 0.1{ }^{\circ} \mathrm{C}$ para a variável temperatura, com um intervalo de medição que vai de $-20^{\circ} \mathrm{C} \mathrm{a}+60^{\circ} \mathrm{C}$ e para a umidade relativa do ar apresenta uma precisão de $\pm 1 \%$.

\section{Procedimentos em laboratório}

Após as coletas de campo, procedeu-se à etapa em laboratório, sendo utilizado uma estufa a uma temperatura de $75{ }^{\circ} \mathrm{C}$, até a estabilização do seu peso seco. Após a secagem, as amostras foram imediatamente pesadas para determinação de sua respectiva massa seca. Da resultante da razão entre a diferença da massa úmida com a massa seca, na base seca, foi determinada a umidade do combustí- 
vel e então transformado para porcentagem, conforme a seguinte equação:

$$
U M C=\frac{P u-P s}{P s} * 100
$$

Em que:

UMC: Umidade do Material Combustível (\%);

$\mathrm{Pu}$ : massa úmida $(\mathrm{g})$; e

Ps: massa seca (g).

\section{Processamento e análise dos dados}

Foi realizada análise de correlação de Pearson entre as variáveis meteorológicas e a umidade do material combustível para estabelecer as relações entre as variáveis. Após análise de correlação, foram realizadas análises de regressão linear para a estimativa da umidade do material combustível em função das variáveis meteorológicas. Antes do ajuste das equações, as variáveis foram testadas para verificação das condicionantes da regressão.

$\mathrm{Na}$ modelagem para descrever a relação entre as variáveis meteorológicas e a umidade do material combustível, foram testados nove modelos matemáticos (Tabela 1).

Tabela 1 - Modelos utilizados na estimativa da umidade do material combustível (UMC) com base em variáveis meteorológicas.

\begin{tabular}{c|l}
\hline $\mathbf{N}^{\circ}$ & \multicolumn{1}{|c}{ Modelo } \\
\hline 1 & $\operatorname{Ln} U M C=b_{0}+b_{1} * T$ \\
2 & $\operatorname{LnUMC}=b_{0}+b_{1} * U R$ \\
3 & $U M C=b_{0}+b_{1} * T$ \\
4 & $U M C=b_{0}+b_{1} * U R$ \\
5 & $U M C=b_{0}+b_{1} * V$ \\
6 & $U M C=b_{0}+b_{1} * T+b_{2} * U R$ \\
7 & $U M C=b_{0}+b_{1} * T+b_{2} * V$ \\
8 & $U M C=b_{0}+b_{1} * U R+b_{2} * V$ \\
9 & $U M C=b_{0}+b_{1} * T+b_{2} * U R+b_{3} * V$ \\
\hline
\end{tabular}

Legenda: UMC é o teor de umidade do material combustível em \%; T é a temperatura do ar em ${ }^{\circ} \mathrm{C}$; UR é a umidade relativa do ar em \%; V é a velocidade do vento em m.s-1; Ln é o logaritmo neperiano e; b0, b1, b2 e b3 são os coeficientes de regressão.
Para a modelagem da carga do material combustível $\left(\mathrm{Kg}_{\mathrm{g}} \mathrm{ha}^{-1}\right)$ foram utilizados os modelos apresentados na tabela 2 .

Tabela 2 - Modelos utilizados na estimativa da carga de material combustível (CMC) com base na espessura da manta.

\begin{tabular}{c|c}
\hline $\mathbf{N}^{\circ}$ & \multicolumn{1}{|c}{ Modelo } \\
\hline 1 & $C M C=b_{0}+b_{1} * \ln (E S P)$ \\
2 & $C M C=b_{0}+b_{1} *(E S P)+b_{2} *(E S P)^{2}$ \\
3 & $C M C=b_{0}+b_{1} * \sqrt{(E S P)}$ \\
4 & $C M C=b_{0}+b_{1} *(E S P)$ \\
5 & $C M C=a *(E S P)^{b}$ \\
6 & $C M C=b_{0}+b_{1} *(E S P)+b_{2} *(D A P)$ \\
7 & $C M C=b_{0}+b_{1} *(E S P)+b_{2} *(D A P)$ \\
8 & $C M C=b_{0}+b_{1} *(E S P)+b_{2} *($ DAP $)$ \\
& $+b_{3} *(N a r v)$ \\
9 & $C M C=b_{0}+b_{1} * \ln (E S P)+b_{2}$ \\
& $*(D A P)$ \\
10 & $C M C=b_{0}+b_{1} * \ln (E S P)+b_{2}$ \\
& $*($ DAP $)+b_{3} *($ Narv $)$ \\
\hline
\end{tabular}

Legenda: CMC é a carga do material combustível (kg.m-1); ln o logaritmo neperiano; ESP é a espessura da manta; DAP o diâmetro a altura do peito; Narv o número de árvores e; b0, b1, b2 e b3 os coeficientes de regressão.

Os modelos foram analisados conforme os valores do Coeficiente de determinação ajustado ( $\left.\mathrm{R}^{2} \mathrm{aj}\right)$, os valores do Erro padrão da estimativa percentual (Syx\%).

\section{RESULTADOS E DISCUSSÃO}

\section{Estimativa da umidade do material combustível}

Durante o período das coletas, a velocidade do vento variou de 0,0 a $2,00 \mathrm{~m} \cdot \mathrm{s}^{-1}$, a umidade relativa do ar teve uma variação de 59,40 a $78,10 \%$, a temperatura de 26,11 a $31,60{ }^{\circ} \mathrm{C}$ e a umidade do material combustível de 12,76 a $60,15 \%$, conforme pode ser observado na tabela 3 .

Tabela 3 - Estatísticas descritivas das variáveis meteorológicas e umidade do material combustível observadas durante as coletas.

\begin{tabular}{|c|c|c|c|c|}
\hline Variáveis & $\begin{array}{l}\text { Umidade do com- } \\
\text { bustível (\%) }\end{array}$ & $\begin{array}{c}\text { Temperatura } \\
\left({ }^{\circ} \mathrm{C}\right)\end{array}$ & $\begin{array}{c}\text { Umidade relativa } \\
\text { do ar }(\%)\end{array}$ & $\begin{array}{c}\text { Velocidade do vento } \\
\left(\mathrm{m}^{\left.-\mathrm{s}^{-1}\right)}\right.\end{array}$ \\
\hline Valor mínimo & 12,76 & 26,11 & 59,40 & 0,00 \\
\hline Valor máximo & 60,15 & 31,60 & 78,10 & 2,00 \\
\hline Média & 28,37 & 30,14 & 67,06 & 0,42 \\
\hline Desvio padrão & 7,58 & 1,19 & 4,95 & 0,53 \\
\hline Erro padrão & 0,74 & 0,11 & 0,48 & 0,05 \\
\hline
\end{tabular}


As correlações entre as variáveis medidas estão apresentadas na tabela 4 . Pode-se observar que a correlação obtida entre UMC e a temperatura foi inversa de $-0,81$, e uma correlação direta entre a UMC e a umidade relativa do ar de 0,80 . Enquanto entre a umidade do material combustível e a velocidade do vento, a correlação foi bem abaixo das demais $(-0,17)$, estando inversamente relacionada. Em estudo semelhante na região sul do Brasil e testando duas diferentes metodologias, Alves et al. (2009), obtiveram correlação positiva com a umidade relativa $(\mathrm{r}=0,4$ e 0,81$)$ e inversa com a temperatura do ar $(r=-0,45$ e $-0,79)$.

Batista (1984) e Gambiza et al. (2005) citam que os materiais combustíveis vivos e mortos respondem de forma diferente diante do clima, onde os materiais vegetais vivos possuem a umidade mais constante que do material morto, e por conta dessa instabilidade o material combustível morto propaga o fogo mais rapidamente. Segundo Chuvieco et al. (2002) a umidade do material combustível é influenciada pela interação fisiológica da planta com as diferentes condições de umidade do solo, enquanto a umidade de combustíveis mortos está mais relacionada com os fatores meteorológicos locais.

Tabela 4 - Correlações entre as variáveis meteorológicas e a umidade do material combustível.

\begin{tabular}{c|c|c|c|c}
\hline Variáveis & UMC & T & UR & V \\
\hline UMC & 1,00 & - & - & - \\
T & $-0,81$ & 1,00 & - & - \\
UR & 0,80 & $-0,98$ & 1,00 & - \\
V & $-0,17$ & 0,46 & $-0,46$ & 1,00 \\
\hline
\end{tabular}

Legenda: T é a Temperatura do ar $\left({ }^{\circ} \mathrm{C}\right)$; UR a Umidade relativa do ar (\%); V é a Velocidade do vento (m/s) e; UMC a Umidade do material combustível.

Dentre os modelos avaliados para a estimativa da umidade do material combustível em função das variáveis meteorológicas, os melhores ajustes foram observados nas equações 7,8 e 9 . O modelo 7 utiliza como variável independente a temperatura e a velocidade do vento, o modelo 8 apresenta a umidade relativa do ar e velocidade do vento, e no modelo 9 as variáveis independentes foram a temperatura, a umidade relativa do ar e a velocidade do vento.

O modelo 7 apresentou um valor de coeficiente de determinação ajustado ( $\mathrm{R}^{2}$ aj) de 0,67 e os modelos 8 e 9 um $\mathrm{R}^{2}$ aj ligeiramente inferior de 0,65 , conforme se observa na tabela 5 . O modelo 5 , que leva em consideração para estimativa da umidade do material combustível apenas a velocidade do vento, apresentou o valor de $\mathrm{R}^{2}$ aj bem abaixo dos demais $(-0,02)$. Tal comportamento pode ser explicado pela baixa correlação da velocidade do vento na variação da umidade do material combustível. Alves et al. (2009) encontraram valores de $\mathrm{R}^{2}$ aj de $0,86 \mathrm{em}$ modelos considerando a velocidade do vento e a temperatura $\left(U M C=b_{0}+b_{1} * T+b_{2} * V\right)$ e de 0,75 considerando temperatura, umidade relativa e velocidade do vento $\left(U M C=b_{0}+b_{1} * T+b_{2} *\right.$ $\left.U R+b_{3} * V\right)$. Cabe destacar que o material combustível predominante no trabalho de Alves et al. (2009) foi de acículas de Pinus, as quais diferenciam das características de heterogeneidade dos combustíveis presentes no Cerrado.

Os resultados encontrados, demonstram que a umidade do material combustível de Cerrado stricto sensu pode ser estimada através de modelos de regressão. A avaliação da umidade do material combustível deve também ser avaliada nas outras estações do ano em que os resultados dos melhores modelos poderão subsidiar ações do uso do fogo controlado, prevenção e combate de incêndios florestais.

Tabela 5 - Estatísticas obtidas para os modelos de regressão ajustados para a determinação da umidade do material combustível em função das variáveis meteorológicas.

\begin{tabular}{c|c|c|c|c|c|c}
\hline \multirow{2}{*}{$\mathbf{N}^{\circ}$} & \multirow{2}{*}{$\mathbf{R}_{\text {aj }}$} & \multirow{2}{*}{$\mathbf{S}_{\mathbf{y x} \%}$} & \multicolumn{4}{|c}{ Coeficientes } \\
\cline { 4 - 7 } & & & $\mathbf{b}_{\mathbf{0}}$ & $\mathbf{b}_{\mathbf{1}}$ & $\mathbf{b}_{\mathbf{2}}$ & $\mathbf{b}_{\mathbf{3}}$ \\
\hline 1 & 0,56 & 15,89 & 6,948369 & $-0,125139$ & - & - \\
2 & 0,54 & 16,77 & 1,512825 & 0,0247216 & - & - \\
3 & 0,63 & 14,63 & 122,6609 & $-3,249982$ & - & - \\
4 & 0,62 & 14,92 & $-18,8085$ & 0,6464247 & - & - \\
5 & $-0,02$ & 24,52 & 27,79215 & $-3,638816$ & - & - \\
6 & 0,61 & 14,61 & 90,08412 & $-2,508787$ & 0,15195 & - \\
7 & 0,67 & 13,49 & 134,0297 & $-3,726779$ & 5,471016 & - \\
8 & 0,65 & 13,91 & $-27,70003$ & 0,7361854 & 5,193506 & 5,486685 \\
9 & 0,65 & 13,45 & 98,24391 & $-2,913198$ & 0,16707 & - \\
\hline
\end{tabular}

Legenda: $\mathrm{N}^{\circ}$ é o número do modelo; $\mathrm{R}^{2}$ aj é o coeficiente de determinação ajustado; e Syx\% são os valores de erro padrão da estimativa e; b0, b1, b2 e b3 os coeficientes do modelo. 


\section{Estimativa da carga de material combustível}

Na tabela 6 são apresentados os resultados dos ajustes dos modelos para a estimativa da carga do material combustível. Dentre os modelos avaliados, os modelos 6 e 7 foram os que apresentaram os melhores ajustes para a estimativa da carga do material combustível. A espessura da manta foi a variável que mais contribuiu no ajuste, entretanto as variáveis dendrométricas (DAP e densidade de árvores) contribuíram para modelos com maior R2aj e menores erros padrões da estimativa (Syx\%).

Tabela 6 - Carga do material combustível superficial em função da espessura da manta e variáveis dendrométricas.

\begin{tabular}{c|c|c|c|c|c|c}
\hline \multirow{2}{*}{$\mathbf{N}^{\circ}$} & \multirow{2}{*}{$\mathbf{R}_{\text {aj }}^{2}$} & \multirow{2}{*}{$\mathbf{S}_{\mathbf{y x} \%}$} & \multicolumn{4}{|c}{ Coeficientes } \\
\cline { 4 - 7 } & & $\mathbf{\mathbf { b } _ { \mathbf { 0 } }}$ & $-4.270,590$ & $14.460,032$ & $\mathbf{b}_{\mathbf{1}}$ & - \\
\hline 1 & 0,58 & 45,72 & $3.829,440$ & $-1.517,253$ & $1.177,542$ & - \\
2 & 0,66 & 41,10 & $-20.223,729$ & $18.227,289$ & - & - \\
3 & 0,61 & 43,71 & $-5.639,709$ & $5.542,410$ & - & - \\
4 & 0,64 & 42,15 & $1.660,400$ & 1,589 & - & - \\
5 & 0,55 & 42,48 & $11.072,084$ & $3.625,580$ & $-2.028,808$ & - \\
6 & 0,78 & 33,28 & $2.620,970$ & $4.116,571$ & $-128,808$ & - \\
7 & 0,74 & 36,08 & $-1.459,016$ & $3.876,324$ & $-92,542$ & 1,430 \\
8 & 0,74 & 52,02 & $4.431,122$ & $10.201,688$ & $-137,521$ & - \\
9 & 0,68 & 67,98 & 707,207 & $9.456,633$ & $-104,629$ & 1,351 \\
10 & 0,69 & 58,11 & & &
\end{tabular}

As características dendrométricas, bem como a espessura da manta, podem ser aplicadas para o desenvolvimento de modelos mais precisos para a quantificação da carga do material combustível, tendo em vista os valores consideráveis de $\mathrm{R}^{2} \mathrm{aj}$. No entanto, em decorrência da escassez de trabalhos envolvendo a estimativa de características do material combustível no Cerrado, novos estudos devem ser realizados.

Grande parte dos trabalhos desenvolvidos no Brasil relacionados a quantificação da carga e estimativa da umidade do material combustível foram realizados em áreas com reflorestamentos de Pinus e Eucalyptus, sendo praticamente inexistentes nas

a)

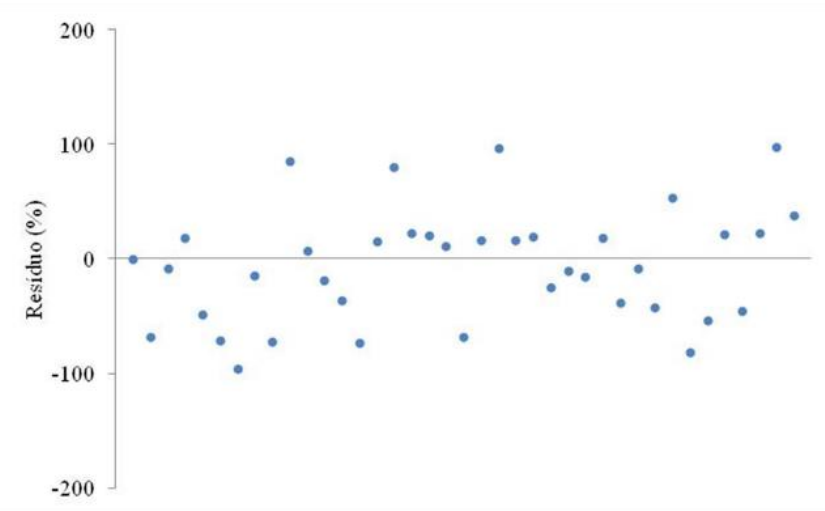

áreas de Cerrado. Em cultivos de Pinus, Souza et al. (2003) obtiveram equações de regressão com uma variação nos valores de $\mathrm{R}^{2}$ aj de 0,64 a 0,69. Também em cultivos de Pinus no sul do Brasil, Beutling et al. (2012) apresentaram valores de $\mathrm{R}^{2}$ aj para estimativa de carga total de material combustível, variando de 0,59 a 0,68 .

$\mathrm{Na}$ figura 5 são apresentados os gráficos de resíduo dos modelos 6 e 7 utilizados para a estimativa da carga do material combustível. Nos gráficos não se observam grandes diferenças, porém o modelo 7 apresenta uma ligeira melhora, em relação ao modelo 6.

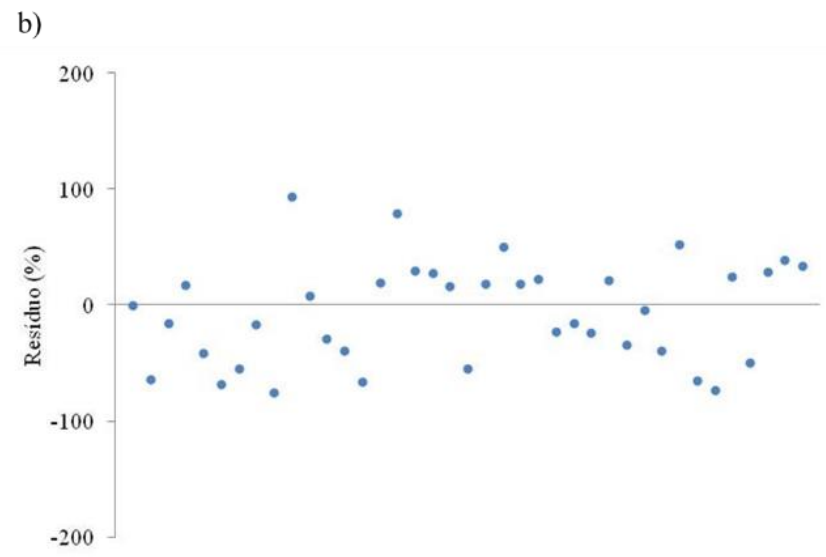

Figura 5 - Resíduo dos modelos de número 6 (a) e 7 (b) desenvolvido para a estimativa da carga de material combustível. 


\section{CONCLUSÕES}

Com base nos resultados apresentados pode-se concluir que:

O melhor modelo de regressão ajustado para a estimativa da umidade do material combustível foi o modelo que utilizou como variáveis dependentes a temperatura e a velocidade do vento $(U M C=$ $\left.b_{0}+b_{1} * T+b_{2} * V\right)$ com um coeficiente de determinação ajustado ( $\mathrm{R}^{2}$ aj) de 0,67 e um erro padrão da estimativa (Syx\%) de 13,49\%.

Para a estimativa da carga do material combustível o modelo que utilizou como variáveis dependentes a espessura da manta e diâmetro a altura do peito $\left(C M C=b_{0}+b_{1} *(E S P)+b_{2} *(D A P)\right)$ foi o que apresentou um melhor ajuste com um $\mathrm{R}^{2}$ aj de 0,78 e Syx $\%$ de $33,28 \%$.

\section{REFERÊNCIAS BIBLIOGRÁFICAS}

ALVES, M.V.G.; BATISTA, A.C.; SOARES, R.V.; KOEHLER, H.S.; PEREIRA, J.F. Modelagem da umidade do material combustível, baseado em variáveis meteorológicas. Floresta, Curitiba, PR, v.39, n.1, p.167-174, 2009.

BATISTA, A.C. Determinação da umidade do material combustível sob povoamentos de Pinus taeda. 1984.73p. Dissertação (Mestrado em Engenharia Florestal), Universidade Federal do Paraná, Curitiba-PR.

BEUTLING, A.; BATISTA, A.C.; STOLLE, L.; TETTO, A.F.; ALVES, M.V.G. Caracterização e modelagem de material combustível superficial em povoamentos de Pinus elliottii. Revista Floresta, Curitiba, v.42, n.3, p.443-452, 2012.

CHUVIECO, E.; RIANO, D.; AGUADO, I.; COCERO, D. Estimation of fuel moisture content from multitemporal analysis of Landsat Thematic Mapper reflectance data: Applications in fire danger assessment. International Journal of Remote Sensing, v.23, p.2145-2162, 2002.

GAMBIZA, J.; CAMPBELL, B.M.; MOE, S.R.; FROS P.G.H. Fire Behaviour in a Semi-arid Baikiaea plurijuga Savanna Woodland on Kalahari sands in western Zimbabwe. South African Journal of Science, v.101, p. 239-244, 2005.

Instituto Nacional de Meteorologia. Normais Climatológicas de 1961 a 1990. INMET. Brasília, 1992.

KLINK, C.A.; MACHADO, R.B. A Conservação do Cerrado Brasileiro. Megadiversidade, Brasília, DF, v.1, n.1, 2005.

PEREIRA JUNIOR, A.C. Métodos de geoprocessamento na avaliação da susceptibilidade do cerrado ao fogo. 2002, 97 p. Tese (Doutorado em Ciências da área de Concentração em Ecologia e Recursos naturais) Universidade Federal de São Carlos, São Carlos, SP.
PIVELLO, V.R.; OLIVERAS, I.; MIRANDA, H.S.; HARIDASAN, M.; SATO, M.N.; MEIRELLES, S.T. Effect of fires on soil nutrient availability in an open savana in Central Brazil. Plant Soil, v.337, p.111-123, 2010.

RAMOS, P.C.M. Sistema nacional de prevenção e combate aos incêndios florestais. In: Anais do I Fórum Nacional sobre Incêndios Florestais / III Reunião Conjunta IPEF-FUPEF-SIF. Anais. IPEF, 1995. p.29-38.

Secretaria do Planejamento e da Modernização da Gestão Pública (Seplan). Atlas do Tocantins: subsídios ao planejamento da gestão territorial. 6. ed. rev. Palmas: Seplan, 2012. $80 \mathrm{p}$.

SOARES, R.V.; BATISTA, A.C.; TETTO, A.F. Incêndios florestais: controle, efeitos e uso do fogo. Curitiba: 255p. 2007.

SOUZA, L.J.B. DE; SOARES, R.V.; BATISTA, A.C. Modelagem do material combustível superficial em povoamentos de Eucalyptus dunnii, em Três Barras, SC. Cerne, Lavras, v.9, n.2, p.231-245, 2003. 